\title{
ENHANCING STUDENTS CRITICAL READING SKILLS IN TEACHING ARGUMENTATIVE ESSAY
}

\author{
Richard Manuputty \\ English Study Program FKIP Pattimura University Ambon \\ Email: rismanu2015@gmail.com
}

\begin{abstract}
Stereotypically, the teaching of writing is separated from reading subjects. As the results, many students are found to be passive and not critical in writing. This action research looks into the effectiveness of enhancing students' critical reading in writing argumentative essays. It is investigating whether the genre-based cognitive reading and approach applied brings significant impacts in students' writing ability? The results of the study indicated some moderate changes in writing argumentative skills which were analyzed and assessed through content analysis over two complete writing products submitted after two complete learning cycles. Some students of $(\mathrm{N}=18)$ are at developing learning stage of becoming critical in writing but not yet fluently in making strong arguments for their opinions. Some have already shown capability to organize their thoughts better in thesis writing but not successfully developed them with facts from their own factual experiences in supporting and defending their stands and arguments in development writing stage. The instructional learning system is found to be effective though obviously much time is needed for comprehending texts, and more writing practice is required before students can eventually perform better argumentative essays.
\end{abstract}

Keywords: Critical Reading, Argumentative, Reading-Writing

\section{Introduction}

It is the reflection on my long teaching experience that many students at lower writing level are struggling in expressing critical ideas and arguments ideas in writing argumentative essays. As the result writing students turn to produce ineffective critical arguments. In other words, they are not responding critically when they disagree with an author's point of view. This problem of academic writing is occurred as an indirect consequence of instructional learning system that paying too much attention on building descriptive and procedural types of writing, and the fact that teaching of Reading is taught separately from writing subject. This receptive knowledge restrains students from becoming creative and critical in thinking when writing. With no analytical literacy skills and strategies for debating, judging and reasoning students turn to be passive in writing performances. Another potential main course of underperformed is the impact of designing curriculums in an integrated way. This contextual literacy problems will stifle critical writing and will discourage 
students in becoming autocratic evaluators for their own writing in higher academic tasks.

The purpose of the study is basically to teach students how to differentiate among being critical reader, passive reader and active reader, to compare the structure of an argumentative text with descriptive-explanatory text types in general. The specific reading objectives of this study are based on Woodcock's proposes of teaching reading (2004); First, to teach students to be able to understand a critical reading text by explaining the topics and main ideas, and by identifying most of evidence that support the main ideas. Second, to enable students in explaining ideas from the text and make connections to writing assignments. Third, to enable students to explain personal insights, opinions or feelings in relation to the text read. This study therefore, underlined a strong relationship between critical reading and critical writing in which students anticipate and apply their reading knowledge in writing argumentative essay. According to Shanahan (2000), in this association the readers and the writers should have four domains of knowledge. First, knowing about the functions and goals of reading and writing (Metaknowledge). Second, having prior knowledge about substance and content (Domain or world knowledge); Third, knowing about letter recognition and grammar or rules for sentence construction (Universal attributes knowledge); and forth, have knowledge and skill to negotiate reading and writing: predicting, questioning, recalling, and trying to find analogies. (Procedural Knowledge).

The study is designed to address the following research questions: 1). In what context can critical reading exercises can increase students writing performance of argumentative essay?, and 2).What are the students' perceptions and commands about the instructional system applied?

The hypothesis of this study is; treatment by way of having students practiced analyzing and evaluating texts critically through the use of analytical guideline to questions provided at additional extra-curricular time, lower level writing students with insufficient knowledge in disputing arguments will eventually perform better at producing critical argumentative essays.

\section{Literature Review}

Unlike descriptive writing that the writers simply provide description of factual information, a critical writer needs to weigh up the evidence and arguments of others from reading sources. In this type of writing, student writers need to consider the quality of the evidence, provide comments for both positive and negative points of view, and decide to take useful argument/s to support and built their own writing. According to University of Birmingham's Study Guidelines (2015) for critical thinking, reading and writing skills are characterized when the writer firmly rejects or accept a conclusion drawn by other writer, obviously explain the reasons why he/she accepts or rejects it, and logically present the writer's own points of view and evidence to support his/her position. In other words, critical reading and writing skills are 
determined through analyzing of the rhetorical message in a written text whether it is reasonably or logically stated before drawing an inference or making a conclusion. In this instructional system, participating students are expected to apply similar strategies of analytical reading in the same way they structure their text and develop their critical arguments on the issue discussed. In this type of writing, students should be able to develop their thesis statements, provide arguments and reasons, evidence; facts and statistical behind the main point of view (Kearney, V, 2007). In line to this ideal learning situation, Saifer, S. (2018), referred skills of creative thinking in concept of Higher-Order-Thinking as how students should be able to understand, interpret an written information or argument, synthesize to other information and create novice idea/theory of their own. In this context of study, the participating students of argumentative essay writing class are trained through critical reading exercises in an attempt to enhance their critical thinking in performing their writing tasks. Critical reading is not merely reading by skimming for superficial or reading for general information of any text as commonly practiced by many students, instead it is dealing with deeply involvement of students as critical readers in interrogating specific information in relation to 'what, why and how' the authors' opinions and arguments are stated as important sources for ideas and discussions relating to individual area of interest and argumentative topics to write about. The critical reading exercises conducted prior to writing process activities are meant for writing students to learn from the model argument texts how certain processes of important information taken place, actively involve in raising some necessary interrogated questions and make effort in answering questions raised to enhance clarity and comprehension of the readings. Precious related study of integrated thematic readingwriting with EFL college students reported the effectiveness of thematic connection of reading and writing. As the result of the treatment students performed better in both reading and writing skills (Esmaeili, 2002). In support to the learning that integrated reading and writing skills at her Trait Writing Program, Raphael, J (2017) underscored the important of building students' independence since they can control the construction meaning of the text, give more thought of the information read, its purpose and its audience. The approach is important in leaning literacy since students are actively learn to identify themselves as readers and writers'.

\section{Research Methodology Participants}

This classroom action research takes place in my own writing class involved 40 students who enrolled at 2018 academic year, first time registered in argumentative writing course . However, only 18 (Eighteen) are considered eligible completed all reading-writing tasks assigned for one semester (16Xmeetings). The students enrolled are required to have passed reading 1,2 and writing 1,2 as prerequisite courses with minimum grades of $\mathrm{C}$ (Sufficient /Average marks) to be eligible participants of the study.

\section{Procedure}


The procedure of teaching and learning covered one semester long with 16 meetings each lasting 150 minutes; including rationale theories and practices. The class was designed in the following way: $30 \%$ of the time was spent in the direct teaching process of analytical reading ( 4 x meetings); $70 \%$ was for process writing activities (12x meeting for 2 writing projects) spent on two writing projects, and the rest was used for writing reflections and comments.

At initial reading cycle the instructor explained what an argumentative essay is all about theories and generic structure of text. An example text was analyzed while students paid attention to analytical questions on rhetoric devices of text, the author's points of view, and the structure of the text. After that comprehension questions and answered were on discussed with the class. Handouts on materials were photocopied and some notes were power-point presented. Through this learning stage, students are expected to start building comprehension on how a critical reading text is organized and produced. Sample model of analysis and evaluation is practiced in classical approach followed by discussions and comments. For insightful discussion and inputs in academic reading, a reading instructor was invited to be involved at Meeting 4th. The next reading activity was done in groups of 4, in which each group do similar evaluation and criticism activities on the new text. The report of work was presented the next meeting through which 3 results were presented and the rest of the class raised questions that were supported with necessary evidence and examples when giving arguments why they agree or disagree with the other's point of view. The instructor mediated and guided the discussion throughout, clear cut when discussions were swerved or misleading. In the third meeting students are assigned on individual work, in which they select their own readings and present their results of evaluation using power point presentation. Notice that prior to individual presentation students should share and discuss their work with their peers. At meeting fourth, the reading class students are asked to give comments and reasons why they think they are pro or con with arguments that used to support particular claim or point of view. To end the critical reading learning cycle, students are asked to self-reflect on their learning experience. The first meeting of writing cycles 1 (Meeting 5th), I taught students to notice some characteristics that make difference between descriptive writing and critical writing samples of work with the list of the differences are highlighted and explained. The next activity was a text evaluation exercises using rubric for assessment of the argumentative essay in English and Bahasa Version. Comments through discussions are meant to enhance the students' comprehension of the important content and aspects of the genre learned. Power point materials are used for focusing the learning target that is students are ready for kind of text they would produce. The next (Meeting's 6th-10th) was about preparation for making an outline for 1 st project writing. Guideline of writing a planning a five-paragraph essay (two pages long) is designed and complete proposal would be approved before continued with drafting and developing process. It is very important stage in determine the success of project writing in this study, therefore, the readiness of planning will be 
assessed separately. Essay topics are decided by the students but should be around present common issues. When students reached the drafting and development stage, they were asked to apply their procedural knowledge in analyzing texts they produced themselves (self-assessment) and the works of their peers (Peer-assessment). At final stage of writing process, their handed in the revised drafts and had the chance to discuss their work at individual conference with me and received imputes for improvement. Students submitted final revised draft of work and gained the comments and grades for mid semester coursework. In the second cycle of writing project (Meeting 11th-16th) students are support to write about issues around 'English Education: teaching and learning' in which some prompts are provided. Again, procedure and process are repeated as in the first project writing, to be submitted and score as final semester grades the two final scores of writing projects were tabulated, analyzed and assessed both qualitatively and quantitatively. In addition to completion of two writing projects participant students are expected to spend time writing reflections on a bi-project basis and wrote comments on attitudes questionnaires administered at the end of the semester. Data analyzed from the sources documented sought for the changes in the students' ability in writing performance before, during the process of two writing projects, and after the instructional system is implemented.

\section{Table 1. The structure of the intervention}

\begin{tabular}{|c|c|c|}
\hline $\begin{array}{l}\text { Learning cycle } \\
\text { Week } 1 .\end{array}$ & Material & Process \& Activity \\
\hline $\begin{array}{l}\text { Week } 1 \text {. } \\
\text { Introduction to course }\end{array}$ & Reading-writing & What is critical reading \\
\hline $\begin{array}{l}\text { Learning contract } \\
\text { Week 2-4 }\end{array}$ & Essay writing all about & $\&$ argumentative writing type \\
\hline Week 2-4 & Reading for analytical purposes & Discussions and Comments \\
\hline Strategic readings: & Argumentative texts and rubric, & Analytical reading practices \\
\hline Critical thinking Writing & Topic and Issue; arguments \& & Groups and individual readings \\
\hline Evidence \& Arguments & Evidence types & Practices Guideline questions \\
\hline $\begin{array}{l}\text { Analyzing Text Structure } \\
\text { Week 5-10 }\end{array}$ & Week 5-10 & Exercises \& Reflection \\
\hline Project writing 1 & Description vs Argument & Discuss some differences \\
\hline Critical writing & Samples of work vs rubric & Critical vs not critical \\
\hline Planning stages & Five paragraph-essay writing & Questions \& class discussion \\
\hline Reading for writing & Issue vs Thesis statements & Highlighting problem \\
\hline Documenting & Sources \& Citations & Independent reading \& Writing \\
\hline Drafting and development & Free topic \& Prompts & Individual conference \& Self- \\
\hline \multicolumn{3}{|l|}{ Reflection } \\
\hline \multicolumn{3}{|l|}{$\begin{array}{l}\text { Week 11-15 } \\
\text { Proiect writing } 2\end{array}$} \\
\hline $\begin{array}{l}\text { Project writing } 2 \\
\text { weakness }\end{array}$ & $\begin{array}{l}\text { Instructional Review } \\
\text { Reading for writing }\end{array}$ & $\begin{array}{l}\text { Comments problem and } \\
\text { ne issues in English Education }\end{array}$ \\
\hline areas are evaluated & Planning \& Develop & ient $\quad$ Suggested to \\
\hline \& Checklist & & \\
\hline
\end{tabular}

Findings

\section{Changes over project writing cycles}

The changes in writing performance both holistically and analytically are reported using basic descriptive statistics by William Fox's formulas (1979). The data 
were then used to calculate the means and the standard deviation over the eighteen students' final work. A mean score for each student was derived by combining the scores gained over the two final writing projects. The scores were tabulated to determine the average increase in scores on the writing sample as a whole, as well as in three different aspects. The results of mean and standard deviation of total average of the two projects writing counted are; 49 (grader 1) and 64 (grader 2). The finding therefore, suggests an average increase of 14 per cent in general essay writing.

Table 2. Presents students' writing progress holistically:

\begin{tabular}{|c|c|c|c|c|c|c|c|c|c|}
\hline \multirow{2}{*}{ N18 } & \multicolumn{2}{|c|}{ PROJECT 1 } & \multicolumn{2}{|c|}{ PROJECT 2 } & \multicolumn{2}{|c|}{$\begin{array}{r}\text { TOTAL } \\
\text { AVARAGE }\end{array}$} & \multirow{2}{*}{$\begin{array}{c}\text { INCREASE IN } \\
\text { PERCENTAGE }\end{array}$} & \multicolumn{2}{|c|}{ GRADE } \\
\cline { 2 - 6 } & Gdr 1 & Gdr 2 & Gdr 1 & Grdr 2 & Gdr 1 & Gdr 2 & & Gen & Final \\
\hline MEAN & 50,56 & 49,72 & 62,27 & 64,5 & 49,94 & 63,61 & $14 \%$ & & \\
\hline S D & 7,25 & 10,36 & 7,27 & 7,63 & 10,63 & 7,01 & $7 \%$ & & \\
\hline
\end{tabular}

As shown in the following table, besides writing progress in general, changes in analytical aspects are also calculated in average mode. It is revealed that some moderate and small improvements occurred in the composition aspects of Focus and Structure by 0,67 (Mean) and 0,69 (SD); Introduction by 1,2 (Mean) and 0,71 (SD); Evidence by 0,89 (Mean) and 0,68 (SD); Conclusion by 0,72 (Mean) and 0,52 (SD); and aspect of Convention by 1 (Mean) and 0,54 (SD). The result of the study indicates that students' procedural knowledge gained through integration of critical reading in writing argumentative essay was increased after intervention.

Table 3. presents' students' writing progress analytically

\begin{tabular}{|c|c|c|c|c|c|}
\hline \multirow{2}{*}{ N18 } & \multicolumn{5}{|c|}{ Aspects of argumentative essay } \\
\cline { 2 - 6 } & Focus \& Structure & Introduction & Evidence & Conclusion & Conventions \\
\hline MEAN & 0,67 & 1,2 & 0,89 & 0,72 & 1 \\
\hline S D & 0,69 & 0,71 & 0,68 & 0,52 & 0,54 \\
\hline
\end{tabular}

\section{Reflection and Evaluation}

Self-Refection was administered right after the first writing project was read by two writing instructors in which some potential problems that might affect the learning results were highlighted and discussed for improvement in the second writing project cycles. Data from the results of evaluation on students' writing projects of first learning cycle indicates that most students were not yet reached the target of learning, that is 'Meeting standards 'Level 3 of the writing rubric applied. The first potential problem that most students commonly faced was a relatively short time needed in adaptation from the habit of writing that are not based on complementary reading sources into the instructional writing system respectfully, in which students have to know a lot about a particular subject before they can plan and develop a debatable argumentative writing title. At first cycles it is realized that most students write mail based on their declarative knowledge and practical experiences; 
therefore, they faced difficulties in making a clear and strong arguable thesis statement for discussion in planning stage. Most of the introductory paragraph demonstrate unsatisfactory in drawing background for debatable highlighting issues with given arguments and supports both the pro and con sides before the student writers commence their position on their assertion. The second potential problem is concerned with essay development that are not effective in many ways. Most contents of writing aspects were found to be vague in terms of ideas expressed and language usage in making arguments. Most discussions reached only at superficial level of argumentation with little supports from reading sources, therefore many essays were considered weak and not arguable yet in making criticism and judgement about authors thoughts and arguments. Few students demonstrated critical thinking in receiving and rejecting authors 'arguments read with some comments and evidence but supported their own opinions with no evidence, little explanation with weak reasonings. The potential causes of the problems in the first writing cycles are due to; first is related with the insufficient knowledge on topics selected and the incapability of comprehending texts in general, and thus, many are failed in analyzing and judging arguments read in specific. The third problem that commonly appeared in the first writing project was about ineffective ways in wring citations, quotations and paraphrasing of important information from reading texts. Students turned to dominantly use vocabularies from original sources and overuse of quotation marks in citation work instead of making paraphrases. To solve the forementioned problems in the next writing cycles, more analytical and argumentative readings tasks would be addressed. Some critical reading rubric and analytical questions guidelines were highlighted and used to answered some examples of problematic writing aspects commonly found. Discussion on this problematic area use both English and Bahasa so students can internalize the criteria and standards for a good writing compared with their own results of work. At this learning stage, focus was given particularly on the structure and content of argumentation materials and language usage in introduction section, how the thesis statements are written and how evident are used in supporting arguments. Considering the time and students' level of knowledge, topics including prompts within the area of English education were provided and more time was given for independent reading. Some examples of common expressions and language from academic phrase bank are provided during the writing development process. In the process of writing the second project, some practical suggestions and steps are given for students in paraphrasing important information from reading sources. Students would be reminding to use their own words and use English thesaurus when paraphrasing the authors' opinions or important information stated. Reconsidering the degree of reading difficulties and insufficient knowledge of free writing topics many students encountered in the first learning cycle, some topics of common issues in English education are provided in the second cycle. The results of final writing products produced in the second cycle indicated some holistic improvement in defining problems in background information, in organizing ideas in 
text structure, in exposing problems for topic discussion, and in writing thesis statements; although, many of the indications are not considered significant critical writing performances. In fact, none of students' work reached the 'exceeding rubric standards applied by Karen Schalk (2007). At this learning stage, students are not yet considered critical writers yet due to the following situations. First, even though some arguments are understood with acceptable structure but still need to be reorganized and revised with more appropriate grammatical and suitable alternative words, otherwise creates improper repetition. Second, some information behind arguments is explained but not backed with strong supporting evidence. Many do not include personal discernment and experts' justifications in defending their arguments but conceptual definitions. Third, some intake references are written in better way but some citations used create problematic as the results of improper ways in paraphrasing important information from reading sources. In addition, many students turn to take ready cited information's from reading source with unclear explanation.

\section{Students' Overall Comments}

When asked for personal comments, majority students (90\%) claimed to have satisfaction with their prior knowledge gained from analytical reading additional sessions before writing argumentative essays. They expressed self-confidence of having a clear ideas and readiness to write after they learned insightfully learned how to analyze, interpretate and evaluate some reading passages, particularly about structural texts of argumentative texts. With all important analytical reading knowledge gained and after the having practical experience in the first project writing process, many students $(80 \%)$ reported to have well prepared for the next writing project assigned. However, many (75\%) admitted the necessary to have longer time required for understanding authors' arguments expressed in long passages that contain many difficult vocabulary and terms. Some $(70 \%)$ confessed to have straggling in expressing critical thinking in evaluating authors' points of view, in drawing inferences due to the lack of vocabularies, as well as in decoding such information like making distinctions between author's opinions and fact that influenced by opinions. Some said to have difficulties in making strong assertions because of insufficient knowledge and shortage of language. To solve the writing problem faced, almost all (95\%) claim to need more reading time to build knowledge around their writing topics especially in making claim on a highlighting issue and in finding experts' opinions in supporting their own arguments. Interestingly, all of the participating students (100\%) expressed highly attitudes to the instructional system applied that challenging them to read deeply and be more critical in reading for specific purposes and be more critical in expressing arguments. Few students expressed the realization of the needs to be active in reading not only for the purpose of writing assignments but also the need to continue sly maintain critical reading manners.

\section{Discussion}


Based on the findings over the two writing projects produced after the first and the second learning cycles some moderate changes in the way student writers sequence the issues for discussion topics, and the way they plan and develop arguments. Many students became more critical in reading when they are asked to go over the guided strategic questions looking back for miss-interpretation problems or sorts of information they might have overlooked in analytical reading process. In this regard, the role of instructor' and peers' assessments is very central in process writing activities. For example, student writers will re-examine the quality of their reasons and evidence in supporting their arguments when a weakness area is pointed out. Analytical reading process will make writing students realize some of important things learned and will pay close attention to how the authors structured their ideas in making their point clearer for fitting together logical arguments. However, students' writers must spend more time for reading insightfully and deeply before they could make strong arguments and evidence in judging someone's ideas or in strengthening, they're on points of view. Moreover, the strategies for critical reading should help students internalize how claims are attributed and transferred the style and language used when writing their own assignments. 'Strategies for success in academic writing' suggest that in collaborative experiences students come to recognize their unique strengths while cultivating their critical-thinking skills and becoming more effective writers. In the second writing project, some students make improvement in writing introductory paragraph in which issues were highlighted but some are not arguable with experts' justifications, thus, not convincing yet. Few students maintained clear position with quite logical reasoning although some ideas were not expressed insightfully with appropriate vocabularies, and were not fully supported with enough evidence. In my opinion, there are two common weaknesses that caused ineffective critical writing during the intervention. Firstly, is dealing with insufficient time students spent on deep reading for necessary evidence and supports from experts. As the result only little knowledge gained to defend their points of view. Some arguments are clearly stated but not well-supported in detail. In fact, some papers produced were mainly supported with two to three sources, and few submitted with no acknowledgement of sources. Secondly, is dealing with the shortage of strategies in making proper paraphrase. Most students are found to be unfamiliar in making paraphrase during the writing process. Although some guidelines were provided, students obviously need more time to practice critical reading-writing, and to spend deep-insightful reading for specific purposes before they can make better augmenting and paraphrasing. In practice, straggling readers like many of the participating students of this study turn to shortcut ways of reading for supporting their arguments by citing cited materials from articles with little change of wording from its original sources. Dangerously, the quality of citations like this has potential to academic problems of copy right.

The findings of the study indicated that teaching students to analyze, interpret and to critical evaluating text in reading process in writing argumentative essay for 
lower level Writing courses in English Study Programs of our institution is considered to be very effective approach for two reasons; First, students cognitive knowledge of how ideas are organized and express gained through direct strategies gained from the analytical problem and solution models are meaningful since students learned much from the model essays and applied similar strategies in producing their own text of similar genre. These opinions is in line with majority experts in the previous studies, and supported by the majority comments from the students expressed in their self-reflections. First, that having practiced critical readings and understood how the writers organized and exposed themselves when expressing their arguments, helped them ready for producing their own argumentative essays. Interestingly, students confessed positive ideas of having opportunity to practice analyzing and evaluating their peers' work with their fresh-ready knowledge gained from the critical reading exercises. Second, using assessment rubric of argumentative writing and checklists in writing process provided in Bahasa is found to be important guidelines both for the researcher/ instructor in conducting individual conferences, and for students in controlling their ideas at group discussions as well as for peer-self assessment learning process.

\section{Conclusion}

Enhancing students' critical reading exercises prior to writing argument essays enhanced students critical thinking in writing. Active process of exploring information in critical reading for understanding text are considered effective for inspiring for ideas for critical argumentative writing. It can be concluded that although the result of many essays produced are not yet reached a highly sophisticate level as stated in the target standard, this integral strategic of advance literacy skills learning system in this study if continue to practice in higher level writing courses. The findings of the study indicated changes enhanced their critical thinking but not yet cultivate critical reading and writing habit; from passive to active-analytical readers; from factual-descriptive to arguable-analytical thingking writers. Although many students due to the relatively shortage of time, could not yet perform better standardized argumentative essay after the second learning cycle, their cognitive strategies and practical reading-writing experience will bring positive impacts to students' changing of habit; from passive to active-analytical readers; from factualdescriptive to arguable-analytical thinking writers. It needs interminable process that ascertains a changing attitude of reading from surface reading habit to deep reading manner; from blind acceptance of information given, to always examine and filter information for building and strengthening arguments in writing. The more students are exposed to critical thinking in all reading and writing tasks they will eventually be more able to articulate critical thinking and gradually are able to become critical selfevaluators for their own learning. Considering the important to early introduce the learning system with lower-level students, it is suggested to use bi-lingual instruction; English and Bahasa to elicit comprehension towards concepts critical reading, and in order to empower students to perform better in independent writing it is also 
recommended for language instructors to provide critical writing rubric for argumentative essay in both language versions as well. Since critical thinking is needed for human capacity building, it is strongly suggested to EFL practitioners to reform curriculum for teaching academic reading-writing subjects; from discreate subjects teaching approach to team-teaching, and from segregated to integrated approach. This idea is supported by Fitzgerald and Shanahan (2000) as cited in Cho \& Brutt-Griffer (2015) who underscored the important of integrating reading and writing because through these related courses readers and writers can share and connect their meta-cognitive knowledge in performing effective reading and writing tasks.

\section{References}

University of Birmingham ( 2015 ). Critical thinking, reading and writing Skills for academic practice guidelines; slides why think critically and why Critical reading? University of Birmingham.

Hyonsuk Cho \& Janina Brutt-Griffler (2015). Integrated reading and writing: Why think critically?A case of Korean English language learners. State University of New York at Buffalo, USA

Hyland, K. (2004). Genre and Second Language Writing. Ann Arbor: University of Michigan Press.

Hyonsuk Cho \& Janina Brutt-Griffler (2015). Integrated reading and writing: A case of Ko-rean English language learners. State University of New York at Buffalo, USA

Jacqueline, R ( February 27, 2017). Putting Reading and Writing Together for struggling students; Education Northwest. Retrieve from https://educationnorthwest,org.

Kearney, V. (2017). How to write an argumentative essay step by step. Retrieved from http://Letterpile.com

Kruse, M. (2017). Reading and writing HAVEN. Why Teach Genre. Retrieved from http://www.readingandwritinghaven.com/why-teach-genres-and-how

Learning Center (Nov 2014). Analytical reading: How can I think, read, or write more analytically? The University of Sydney. Australia. Retrieve from: http://www.writing.utoronto.ca ladvice/reading-and-researching

Oshima,A. \& Hogue,A. (2006). Writing Academic Emglish: Arhgmentative essay. Pearson Education Inc. New York. USA

Saefer, S ( 2018 ). HOT skills: Developing-higher-order thinking in young learner Pdf. Readleaf Press. Scholar.google.com

Smith.C, Ferms.S \& Russel.L, (2014). The impact of work Integrated Learning on student work readiness. The office for learning and teaching. Curtin University. Scholar.google.com

Schwalm, K (17 April 2007 ) Rubric for the Assessment of the Argumentative Essay. Retrieved from: web.gccaz edu/English/assessment/.../argumentrubric.htm

Pasquarelli, S. L. (2006). Teaching writing genres across the curriculum: Strategies for middle school teachers. Greenwich, Connecticut. USA

University of Leicester. Learning Development Centre. (2013) What is critical writing?.Available from: http://www2.le.ac.uk/offices/ld/resources/writing/ writing-resources/criticalwriting-

Unilearning (2000). Critical reading checklist. Available at http://unilearning. uow.edu.au/ reading/2b.html

Wang, M., Haertel, G., \& Walberg, H. (1993). Synthesis of research: What help students learn ? Educational Leadership, 51(4), Pp.74-83. 
Woodbeck, A. (2014). Assessment of critical reading skills in your classes: Colleage. Residential Reading Faculty, PVCC.

https://www.paradisevalley.edu/sites/default/files/docs

Retrieved

from; al/al_fall_2014_critical_reading.pd 